\title{
Model Test on Bearing Characteristics of Basalt Fiber-Reinforced Concrete Lining
}

\author{
Dao-yuan Wang $\left(\mathbb{D},{ }^{1}\right.$ Jia-suo Qi $\mathbb{D},{ }^{2}$ Guang-yao Cui $\mathbb{D}^{,},{ }^{2}$ Yanling Yang, ${ }^{3}$ and Jie Chang ${ }^{3}$ \\ ${ }^{1}$ Department of Civil Engineering, Hebei Jiaotong Vocational and Technical College, Shijiazhuang, Hebei 050091, China \\ ${ }^{2}$ School of Civil Engineering, North China University of Technology, Beijing 100144, China \\ ${ }^{3}$ The 4th Engineering Co. Ltd., China Railway 16th Bureau Group, Beijing 101400, China \\ Correspondence should be addressed to Jia-suo Qi; qi0530309x@163.com
}

Received 29 November 2019; Accepted 17 February 2020; Published 11 March 2020

Academic Editor: Guoqiang Xie

Copyright (c) 2020 Dao-yuan Wang et al. This is an open access article distributed under the Creative Commons Attribution License, which permits unrestricted use, distribution, and reproduction in any medium, provided the original work is properly cited.

\begin{abstract}
Adding fiber can improve the brittleness of plain concrete. Compared with plain concrete, basalt fiber-reinforced concrete has the advantages of strengthening, toughening, and crack resistance. Compared with steel fiber-reinforced concrete, basalt fiberreinforced concrete has better construction performance. Basalt fiber concrete is a type of inorganic material with environmental protection and high mechanical properties, which has an important mechanical advantage for controlling the deformation of the soft surrounding rock tunnel. Through the indoor model test of mechanical behavior of reinforced concrete and basalt fiberreinforced concrete lining, the bearing characteristics of basalt fiber-reinforced concrete lining was studied. The results show that, compared with reinforced concrete, the initial crack load of basalt fiber-reinforced concrete is increased by $20 \%$; the toughness of lining structure is enhanced by adding basalt fiber, and the lining can still bear large bending moment and deformation after the initial crack appears; after the initial crack appears, the bearing characteristic curve of reinforced concrete lining rises slowly and converges rapidly; the bearing characteristic curve of basalt fiber-reinforced concrete lining rises slowly, and there is no sign of convergence when it reaches 2 times of initial crack load. For the soft surrounding rock tunnel, it is necessary to seal the rock surface as early as possible, provide support as soon as possible, and have a certain deformation capacity. Basalt fiber-reinforced concrete can better meet these needs.
\end{abstract}

\section{Introduction}

With the rapid development of China's infrastructure, traffic tunnels in high altitude, high latitude, and high seismic intensity areas are emerging, and the geological conditions in the tunnel site are complex and changeable, which put forward higher requirements for the mechanical properties of the tunnel support. Fiber-reinforced concrete has excellent performance of strengthening and toughening for soft surrounding rock tunnels that require seal the rock surface as early as possible [1-4], providing support as soon as possible and having certain deformation capacity. Fiberreinforced concrete is an effective supporting material.

Plain concrete is a kind of brittle material with low tensile strength [5-7], which makes it unable to play the role of supporting material in the soft surrounding rock tunnel that needs to have certain deformation capacity. Therefore, adding fiber into plain concrete is deemed to be a reasonable solution to this problem. The use of fiber can not only reduce the costs of tunnel construction but also save the cost of construction time. Adding fiber into plain concrete can enhance the toughness and crack resistance of concrete [8], which is just as well suited to the performance requirements of soft rock tunnel support materials. At present, there are many kinds of fiber admixtures, of which steel fiber is the most commonly used in the structure [9-11], and the steel fiber can enhance the structure and bending fatigue durability of support [12]. Steel fiber-reinforced concrete lining has great advantages in seepage resistance and crack resistance. Song et al. [13] reviewed the impact resistance of steel 
fiber-reinforced concrete through ACI test. The test results have shown that, with the increase of steel fiber content, the toughness of concrete cracking is improved. However, steel fiber also has some problems: construction performance is not high, the dosage is too high, and it is easy to be spheroidized and easily corroded [14]. These minor performance problems sometimes become a massive problem in tunnel construction. Basalt fiber-reinforced concrete not only has exceptional performance in construction performance but also its manufacturing process is very environmentally friendly [15]. In recent years, it is widely welcomed in the application of concrete reinforcement $[16,17]$.

The use of basalt fiber-reinforced concrete was first proposed in a 1998 report, which was published in the Highway Innovations Deserving Analysis project 45 [18]. In this report, the volume content and properties of basalt fiber-reinforced concrete are studied for the first time. Basalt fiber is an environmentally friendly and high-performance inorganic material, which can effectively improve the compressive strength of concrete (the maximum increase is about 17\%) [19] and early strength [20], improve the brittle failure characteristics of concrete and improve the crack resistance [21], and also improve the splitting strength (up to 27\%) and flexural strength (up to 25\%) [22]. Ayub et al. [23] studied the mechanical properties of basalt fiber-reinforced concrete in the splitting tensile strength test. The consequences of maximum compressive strength and split tensile strength of concrete with different basalt fiber volumes have been improved, while the effect of fiber addition on elastic modulus is negligible. The distinctive feature of basalt fiberreinforced concrete is its higher energy absorption capacity and higher ductility after reaching the optimum load [24]. Moreover, basalt fiber is easily dispersed in the concrete mixture without segregation and does not afford to lose its shape due to flexibility, which is different from steel fiber that is difficult to handle and thus form a ball. Therefore, basalt fiber-reinforced concrete support structure has a great mechanical advantage for controlling the deformation of the soft surrounding rock tunnel.

Based on the Dujiashan Tunnel (sericite phyllite) of Guangzhou Gansu Expressway, this paper studies the mechanical behavior of basalt fiber-reinforced concrete support structure under the condition of soft surrounding rock, which is of great significance for the study of deformation control technology of soft surrounding rock tunnel and mechanical properties of basalt fiber-reinforced concrete lining.

\section{Background}

Dujiashan Tunnel of Guangzhou Gansu Expressway is located in Qingchuan County, Guangyuan City. It is a twolane one-way tunnels with $1833 \mathrm{~m}$ long left tunnel and $1886 \mathrm{~m}$ long right tunnel.

2.1. Formation Lithology. The Dujiashan Tunnel site is located at the north end of Longmen Mountain on the northwest edge of the Sichuan Basin and close to Motianling

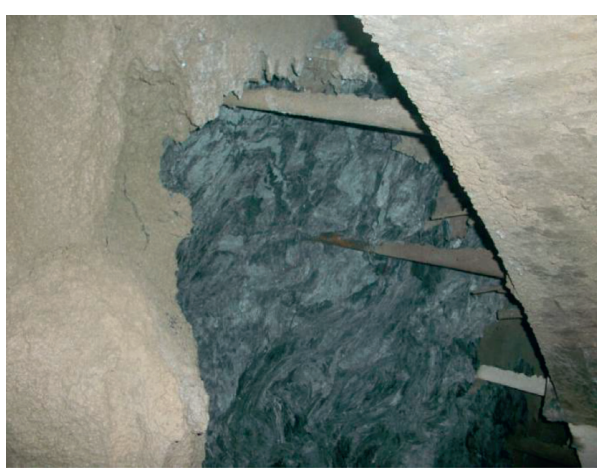

FIGURE 1: Sericite phyllite.

mountain system. The bedrock in the tunnel site is exposed, strata from new to old: the quaternary new system of slopes, collapsed slope accumulation, alluvial proluvial layer, and landslide accumulation layer and the combination of $\mathrm{Pa}$ leozoic Silurian Huangping formation (sand phyllite) and sericite phyllite rock formation.

Part of the Dujiashan Tunnel passes through the Silurian sericite phyllite section (grade $\mathrm{V}$ surrounding rock). The sericite phyllite is yellowish gray, with scale crystalline structure and phyllitic structure, and schistose surface is very developed; soft, nails can be scored; poor joint between layers, the compressive strength is $4.6-6.3 \mathrm{MPa}$, and easily softened by water, which is the main rock layer of the tunnel body, as shown in Figure 1.

2.2. Support Structure Design. The supporting structure of Dujiashan Tunnel is horseshoe section, with a span of $12.82 \mathrm{~m}$ and a height of $10.29 \mathrm{~m}$. The initial support is $\mathrm{I} 20 \mathrm{~b}$ steel frame at $60, \varphi 8$ steel mesh at 20 , and $\varphi 22$ drug roll anchor bolt $+30 \mathrm{~cm}$ thick $\mathrm{C} 25$ shotcrete; the second lining is $45 \mathrm{~cm}$ thick C25 steel-reinforced concrete and $\varphi 22$ steel mesh at 25. It is proposed to use $30 \mathrm{~cm}$ thick CF25 basalt fiber-reinforced concrete instead of the original structural design.

\section{Basic Mechanical Properties Test of Basalt Fiber-Reinforced Concrete}

3.1. Test Content. The test contents and the number and dimensions of the test pieces required for each test are shown in Table 1.

\subsection{Test Results of Compressive Strength and Bending} Strength. The test was carried out by the digital pressure tester (YES-2000) and bending tester (JES-300). The test results of compressive strength and bending strength are shown in Tables 2 and 3.

It can be seen from Tables 2 and 3 that the basalt fiber contributes to the improvement of the compressive strength and the bending strength of the concrete. After the basalt fiber is added to the plain concrete, a reliable network structure is formed in the concrete, which cooperates with the aggregate to bear the stress. When the stress is 
TABLE 1: Test contents.

\begin{tabular}{|c|c|c|c|}
\hline Project & $\begin{array}{l}\text { Specimen size } \\
(\mathrm{mm})\end{array}$ & $\begin{array}{l}\text { Number of C25 plain concrete test } \\
\text { pieces }\end{array}$ & $\begin{array}{l}\text { Number of CF25 basalt fiber-reinforced concrete } \\
\text { test pieces }\end{array}$ \\
\hline $\begin{array}{l}\text { Cube compressive } \\
\text { strength }\end{array}$ & $100 * 100 * 100$ & 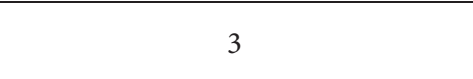 & 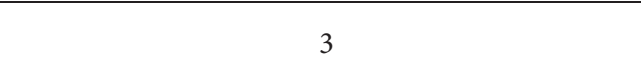 \\
\hline Bending strength & $100 * 100 * 400$ & 3 & 3 \\
\hline Bending toughness & $100 * 100 * 400$ & 0 & 3 \\
\hline
\end{tabular}

Note. Basalt fiber length is $30 \mathrm{~mm}$ and diameter is $18 \mu \mathrm{m}$.

TABLE 2: Test results of compressive strength.

\begin{tabular}{|c|c|c|c|c|}
\hline Type & Average compressive strength (MPa) & Size conversion factor & Conversion strength $(\mathrm{MPa})$ & Growth ratio \\
\hline Plain concrete & 27.182 & 0.95 & 25.823 & 1 \\
\hline $\begin{array}{l}\text { Basalt fiber-reinforced } \\
\text { concrete }\end{array}$ & 32.852 & 0.9 & 29.567 & 1.145 \\
\hline
\end{tabular}

TABLE 3: Test results of flexural strength.

\begin{tabular}{|c|c|c|c|c|}
\hline Type & Average bending strength $(\mathrm{MPa})$ & Size conversion factor & Conversion strength $(\mathrm{MPa})$ & Growth ratio \\
\hline Plain concrete & 3.042 & 0.85 & 2.586 & 1 \\
\hline Basalt fiber-reinforced concrete & 3.571 & 0.85 & 3.035 & 1.174 \\
\hline
\end{tabular}

transmitted from the matrix to the fiber, the fiber consumes energy due to deformation, which improves the toughness and the strength of the concrete.

3.3. Bending Toughness Test Results. The three-point loading test method was carried out using an Instron 25 ton mechanical test machine. The test results are shown in Table 4.

It can be seen from Table 4 that basalt fiber contributes to the improvement of the initial crack strength and toughness of concrete. Toughness $\left(R_{30 / 10}\right)$ of the three specimens exceeds 80 , and the toughness grade is excellent.

\section{Model Test Design}

4.1. Similar Parameter Design. The vertical steel plate model test platform is adopted for the test, as shown in Figure 2. The length of the platform is $4.3 \mathrm{~m}$, the width is $0.5 \mathrm{~m}$, and the height is $3.7 \mathrm{~m}$. It is well known that if the length of the model is 6 times longer than the span of the tunnel, the boundary effect of the model can be ignored, so the geometric similarity ratio can be taken as 20 .

The tunnel lining is simulated with gypsum mixed material, and its elastic modulus is $1.1 \sim 1.65 \times 10^{3} \mathrm{MPa}$, while that of CF25 basalt fiber-reinforced concrete is $2.45 \sim 3.2 \times 10^{4} \mathrm{MPa}$. So the similarity ratio is 20 .

The similarity relationship is derived according to the similarity criteria, and the similarity ratio of other main physical quantities is shown in Table 5.

4.2. Similar Test Materials. Barite powder, river sand, quartz sand, engine oil, and rosin are used to configure similar materials for surrounding rocks. Physical and mechanical parameters of similar materials are shown in Table 6 .

The strength grade of concrete for prototype lining is C25. Gypsum mixture (water-cement ratio is 0.686 ) and
$0.5 \mathrm{~mm}$ finished steel wire mesh (double layer) are used to simulate the lining in the test, as shown in Figure 3.

The actual strength grade of the basalt fiber-reinforced concrete is CF25. The test used gypsum mixture (water cement ratio is 0.611). Basalt fiber (Figure 4) and white emulsion (to improve the adhesion between gypsum and basalt fiber) are used to simulate the lining in the test. The content of basalt fiber is determined as $11.5 \mathrm{~kg} / \mathrm{m}^{3}$ according to the bending toughness test.

The physical and mechanical parameters of reinforced concrete lining and basalt fiber-reinforced concrete lining are shown in Table 7.

4.3. Test Equipment. The test uses vertical steel plate model test platform (Figure 2), miniature pressure box (DYB-1 type, Figure 5(a)), displacement sensor (YHD type, Figure 5(b)), and static strain collector (Figure 6).

4.4. Layout of Measuring Points. The test is divided into 2 groups, reinforced concrete lining and basalt fiber-reinforced concrete lining, with three specimens in each group. Because the lining is symmetrical and the loads are also symmetrical, the measuring points can only be set in half of the lining section. There are 5 typical measuring points (vault, left haunch, middle of left side, and inverted arch), and the arrangement of measuring points is shown in Figure 7.

4.5. Test Process. First, fill the test platform with soil and compact it every $20 \mathrm{~cm}$ until it reaches the bottom height of the test piece; second, bury the lining structure, lay up the test sensor, and fill the soil to the specified height of the surface; finally, load step by step ( $2 \mathrm{t} /$ grade), until the lining is damaged (marked by the appearance of the through crack). 
TABLE 4: Test results of flexural toughness.

\begin{tabular}{lcccc}
\hline Type & \multicolumn{2}{c}{ Test piece number } & JTH-3 & Average value \\
& JTH-1 & JTH-2 & 3.43 & 3.47 \\
Initial crack strength $(\mathrm{MPa})$ & 3.37 & 3.62 & 2.14 & 2.26 \\
Equivalent bending strength $(\mathrm{MPa})$ & 2.38 & 2.27 & 0.52 & 0.53 \\
Bending toughness ratio & 0.59 & 0.48 & 10.3 & 9.63 \\
Toughness index $I_{10}$ & 8.7 & 9.9 & 27.54 & 29.69 \\
Toughness index $I_{30}$ & 31.75 & 29.77 & 86.2 & 100.27 \\
Toughness $R_{30 / 10}$ & 115.25 & 99.35 & & \\
\hline
\end{tabular}

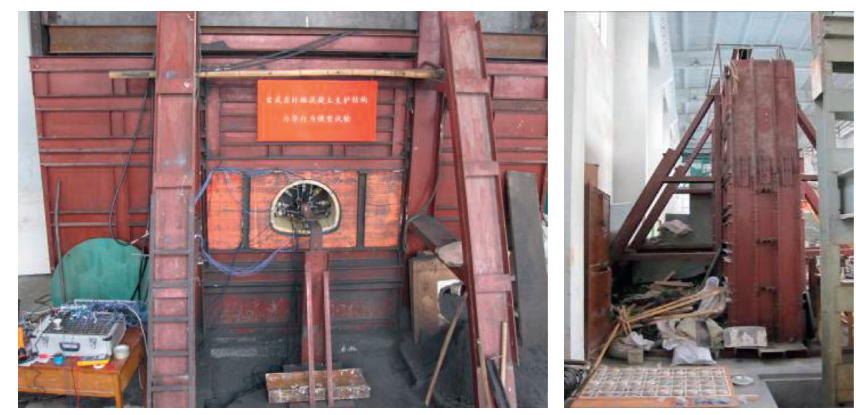

Figure 2: Test platform

TABLE 5: Similarity ratio of main quantities.

\begin{tabular}{lcc}
\hline Type & Physical quantities & Similarity ratio \\
\hline & Elastic modulus & 20 \\
& Compressive/tensile strength & 20 \\
Material properties & Stress & 20 \\
& Strain & 1 \\
& Poisson ratio & 1 \\
Load & Internal friction angle & 1 \\
Geometric characteristics & Density & 1 \\
& Load & 8000 \\
\hline
\end{tabular}

TABLE 6: Physicomechanical parameters of surrounding rock similar material.

\begin{tabular}{|c|c|c|c|c|c|}
\hline Material & Modulus of elasticity (MPa) & Poisson's ratio & $\begin{array}{c}\text { Weight } \\
\left(\mathrm{kN} \cdot \mathrm{m}^{-3}\right)\end{array}$ & Cohesion $(\mathrm{kPa})$ & Friction angle $\left({ }^{\circ}\right)$ \\
\hline Surrounding rock (prototype) & 1210 & 0.41 & 18 & 120 & 23 \\
\hline Similar materials of surrounding rock & 58.5 & 0.42 & 18.5 & 6.1 & 25 \\
\hline
\end{tabular}

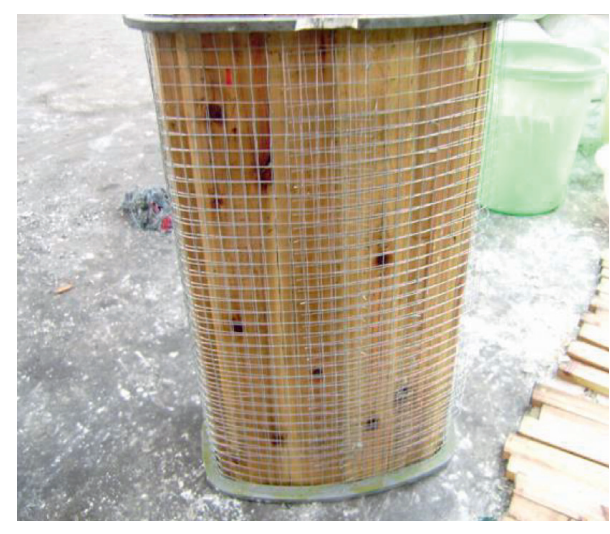

Figure 3: Double-wire mesh for simulation.

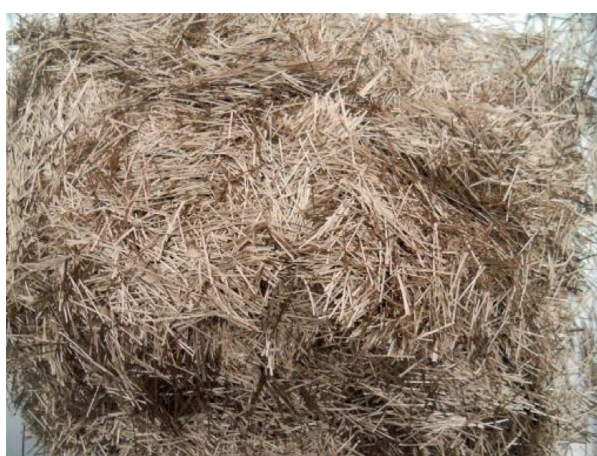

Figure 4: Basalt fiber for simulation. 
TABle 7: Physicomechanical parameters of lining.

\begin{tabular}{llccc}
\hline Material & & Modulus of elasticity (MPa) & Weight $\left(\mathrm{kN} \cdot \mathrm{m}^{-3}\right)$ & Poisson's ratio \\
\hline \multirow{2}{*}{ Reinforced concrete } & Prototype lining & 29500 & 25 & 0.2 \\
& Similar material & 1382 & 24.3 & 0.2 \\
\multirow{2}{*}{ Basalt fiber-reinforced concrete } & Prototype lining & 29500 & 25 & 0.2 \\
& Similar material & 1409 & 24.4 & 0.2 \\
\hline
\end{tabular}

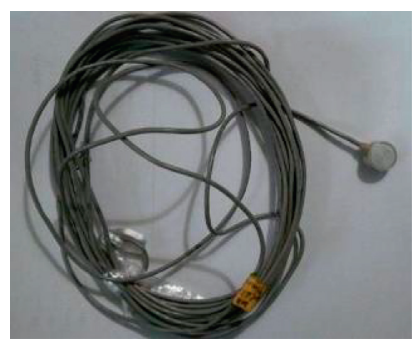

(a)

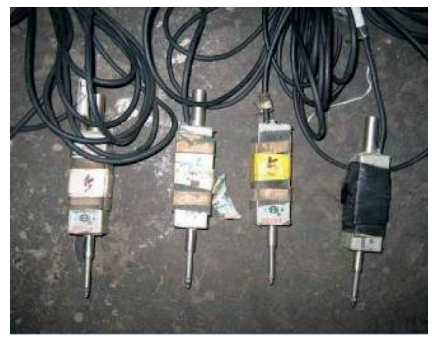

(b)

Figure 5: Test sensor. (a) Miniature pressure box; (b) displacement sensor.

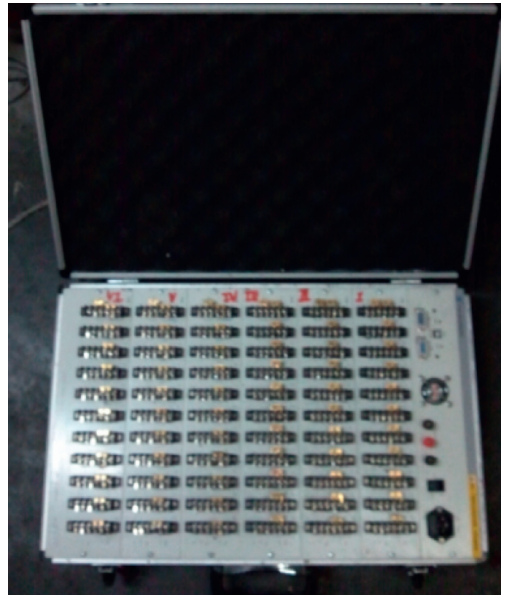

Figure 6: Static strain gauge.

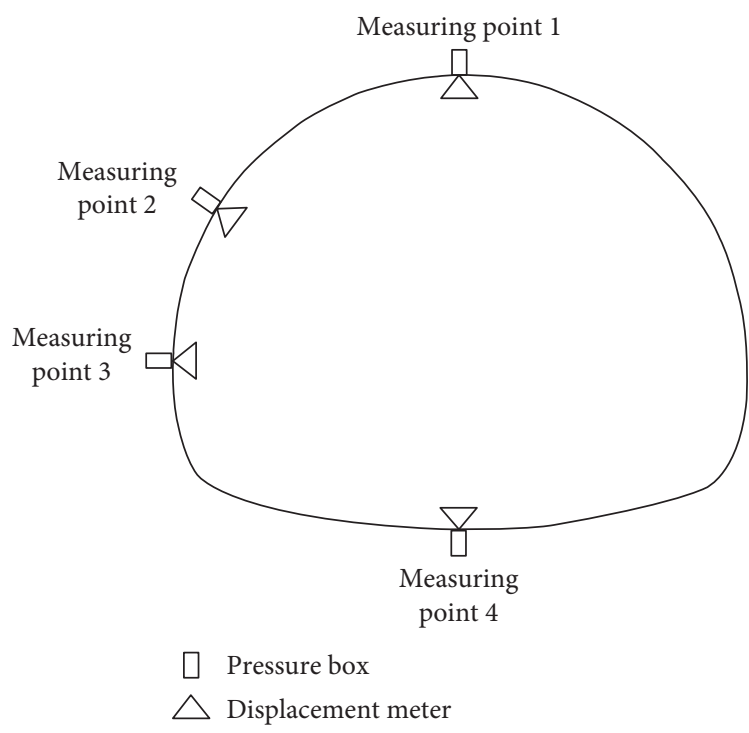

FIGURE 7: Arrangement of measuring point.

\section{Analysis of Test Results}

\subsection{Test Phenomenon}

5.1.1. Reinforced Concrete Lining. Under the action of vertical load, the first crack appears in the inner side of inverted arch, the initial crack load is $10 \mathrm{t}$, and the width and depth of the crack increase with the increase of the load; then the longitudinal crack appears on the vault and the left and right side wall foots; it continues to increase the load, and the crack gradually appears on the left and right sides of haunch, the side walls, and the inverted arch; loading to $20 \mathrm{t}$, when the structure is damaged, there are 9 cracks. The test phenomenon and crack distribution are shown in Figures 8 and 9.

5.1.2. Basalt Fiber Concrete Lining. The first crack appears on the vault of basalt fiber-reinforced concrete lining, and the initial crack load is $12 \mathrm{t}$. Due to the inhibition of basalt fiber, the depth of the crack increases slowly with the increase of the load, and the path of crack is tortuous; then cracks appear in the inverted arch, vault, and side wall. When the load reaches $24 \mathrm{t}$, there are no through cracks in the lining structure and the number of cracks is 13 . The test phenomenon and crack distribution are shown in Figures 10 and 11.

5.2. Radial Pressure. Extract the radial pressure between surrounding rock and lining at each monitoring point during loading at every grade, and draw the curve of radial pressure and load, as shown in Figure 12.

As can be seen from Figure 12, the actual radial pressure acting on the lining is about $30 \% \sim 40 \%$ smaller than the theoretical value, and this part of the load is mainly shared by rock.

It can be seen from Figure 12 that the radial pressure of the lining increase linearly. When the first crack appeared (reaching the initial crack load), the rate of radial pressure growth has started to slow. The stress of basalt fiber- 

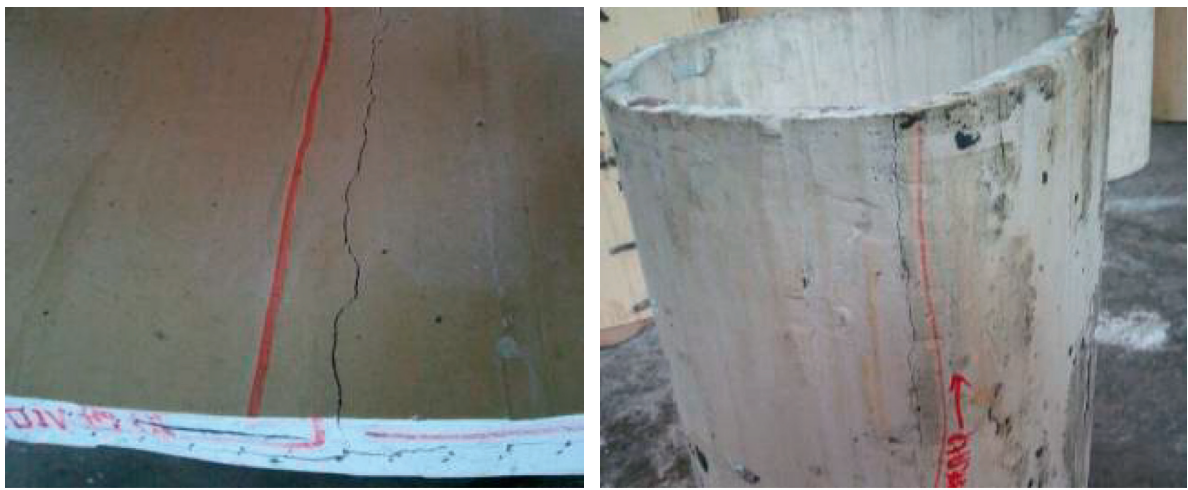

FIGURE 8: Lining cracks of reinforced concrete.

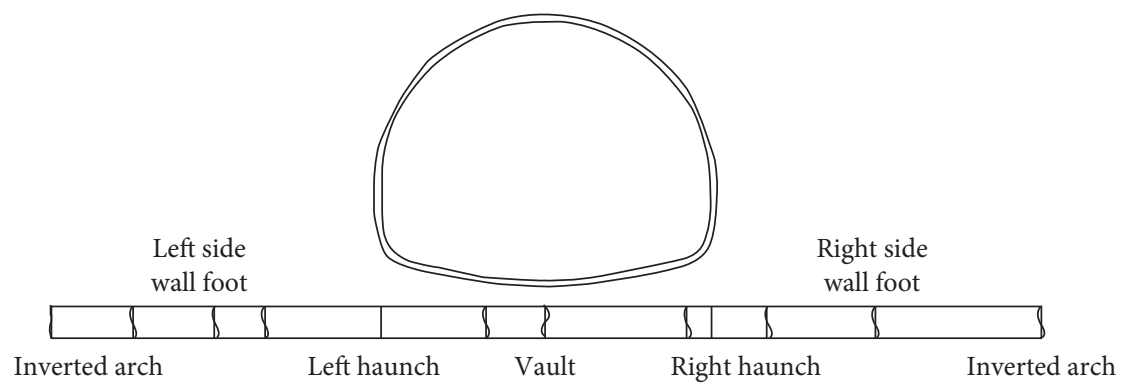

Figure 9: Distribution map of lining cracks of reinforced concrete.
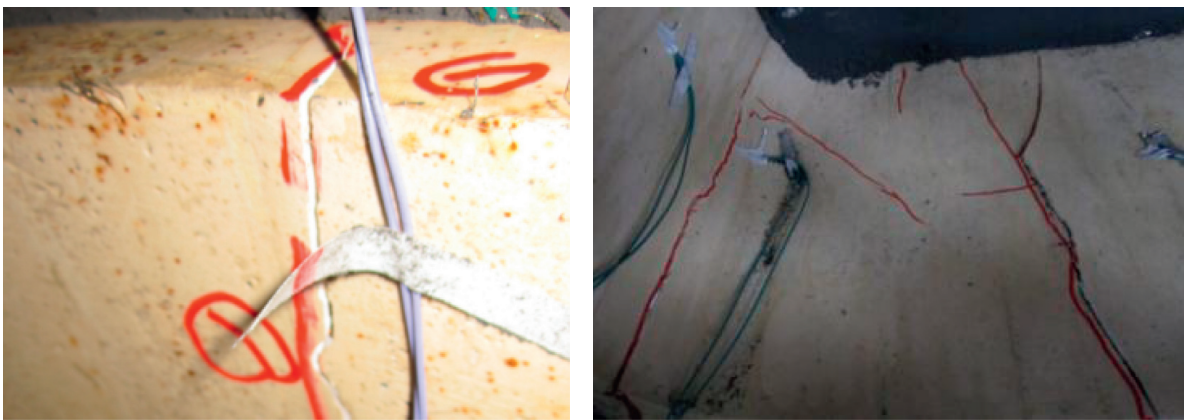

FIGURE 10: Lining cracks of basalt fiber-reinforced concrete.

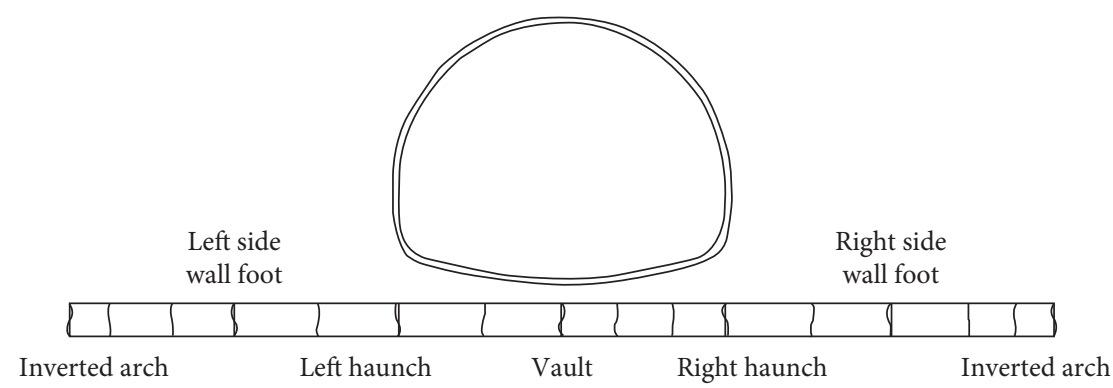

FIGURE 11: Distribution map of lining cracks of basalt fiber-reinforced concrete.

reinforced concrete lining is more uniform than that of reinforced concrete lining, which is mainly due to its good crack resistance and deformation control ability. When the basalt fiber-reinforced concrete lining bears twice the initial crack load, the structure is still intact (when the reinforced concrete lining bears twice the initial crack load, the structure is damaged).

In Figure 12(c), the radial pressure in the middle of the reinforced concrete lining side wall increases sharply when the load is $14 \mathrm{t}$, which is mainly due to the initial cracks in the 


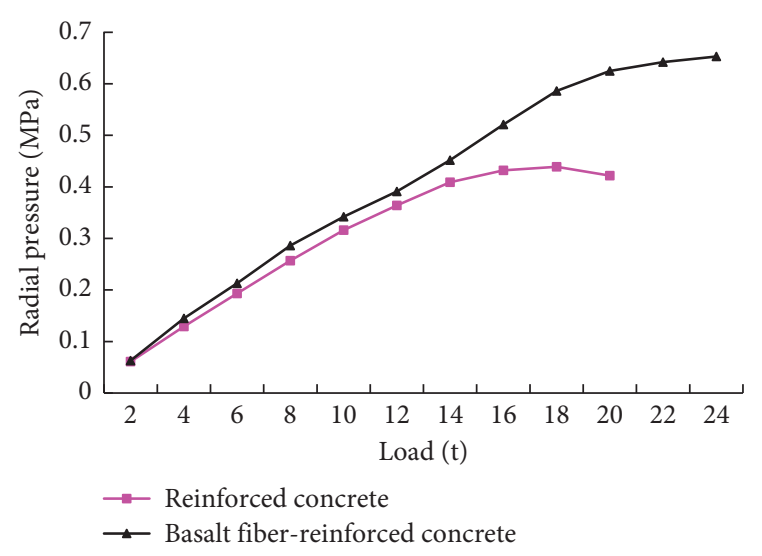

(a)

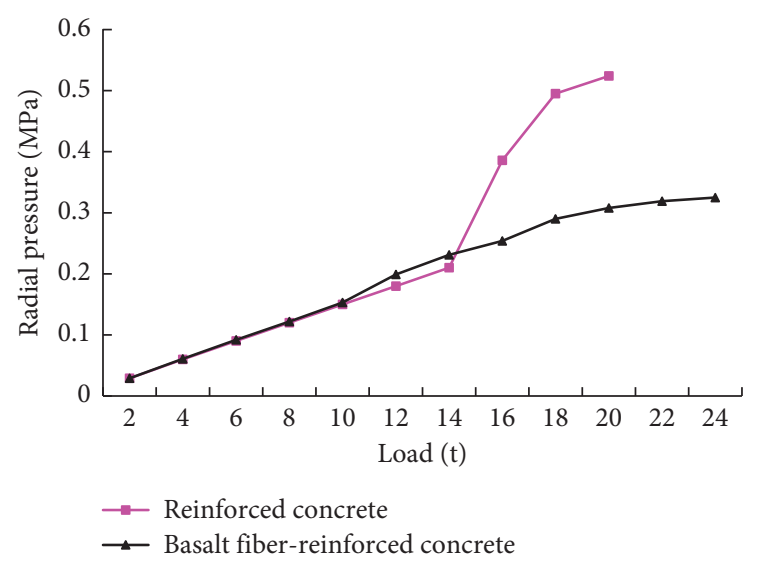

(c)

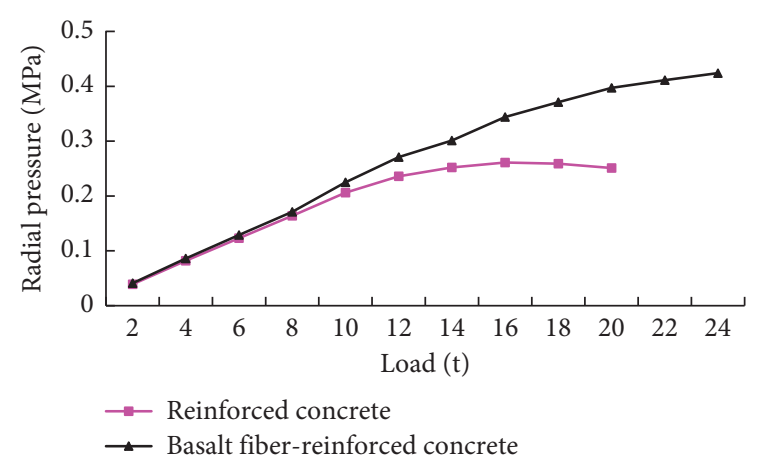

(b)

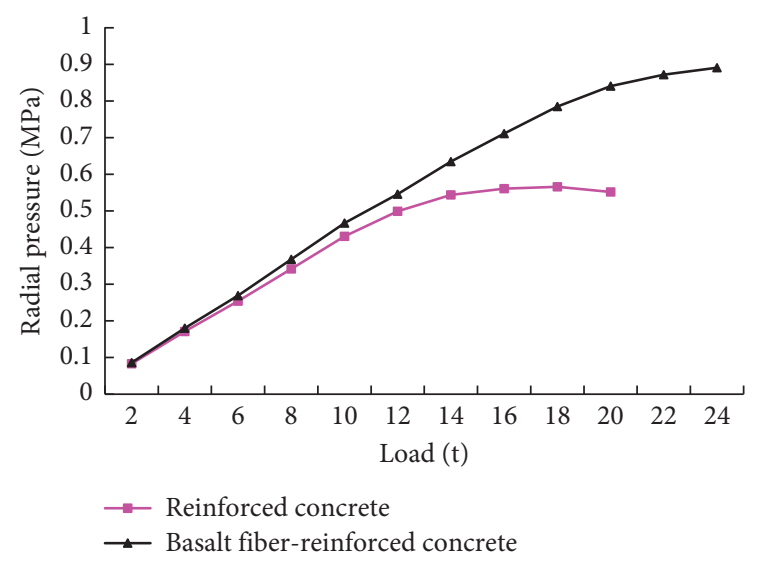

(d)

FIGURE 12: Change curve of the radial pressure and load. (a) Measuring point 1-vault, (b) measuring point 2-haunch, (c) measuring point 3middle of side wall, and (d) measuring point 4-middle of inverted arch.

lining causes the flat rate of the section to suddenly decrease, and the side wall is sharply squeezed toward the surrounding rock, resulting in the sharp increase of the radial pressure here.

5.3. Radial Displacement. Extract the radial displacement at every grade of loading, and draw the curve of the radial displacement and load, as shown in Figure 13.

It can be observed in Figure 13, before the initial crack load is reached, the radial displacement is basically linear with the increase in load. When the initial crack load is reached, the radial displacement growth rate increases obviously, and the reinforced concrete lining is larger than the basalt fiber-reinforced concrete lining. When loaded with the same load, the radial displacement of reinforced concrete lining is larger than that of basalt fiber-reinforced concrete lining. In conclusion, crack resistance, toughness, and deformation control ability of basalt fiber-reinforced concrete lining is better than that of reinforced concrete lining.

5.4. Bearing Characteristics. Extract the radial pressure and displacement at every grade of loading, and draw the curve of bearing characteristic as shown in Figure 14.
It can be seen from Figure 14 that the measuring points at the vault, haunch, and middle of the inverted arch continuously deform towards the inner direction of the tunnel, and the law is basically the same. In the process of loading, the measuring points of the side wall deform towards the surrounding rock continuously, which is different from other measuring points. The bearing characteristics of the basalt fiber lining structure are analyzed by the vault as the representative measuring point of the internal deformation of the structure, and the middle of the side wall as the representative measuring point of the external deformation of the structure.

\subsubsection{Internal Deformation Measuring Point-Vault.} When the initial crack load is reached, the radial displacement growth rate of reinforced concrete lining measurement point increases abruptly, and the radial pressure growth rate slows down. The final load of reinforced concrete lining increases by about 50\% (compared with the initial crack load).

When the initial crack load is reached, the radial displacement growth rate of the basalt fiber-reinforced concrete lining has a certain degree of increase, the radial load growth rate has a slow trend, and the bearing capacity of the 


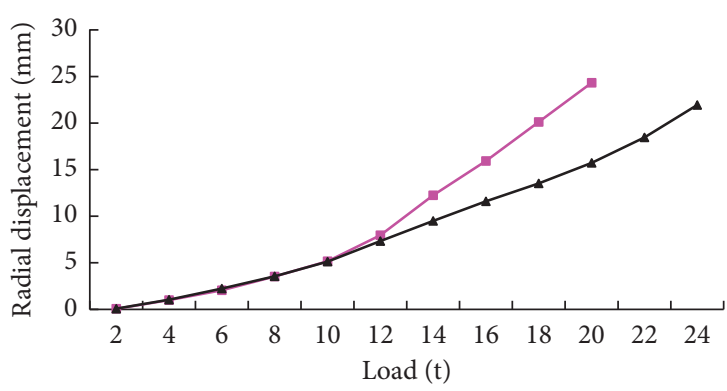

Reinforced concrete

Basalt fiber-reinforced concrete

(a)

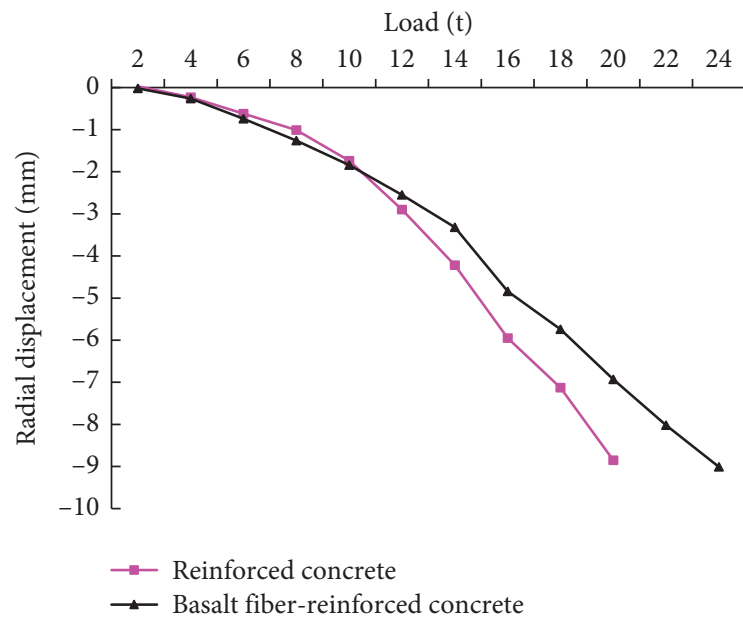

(c)

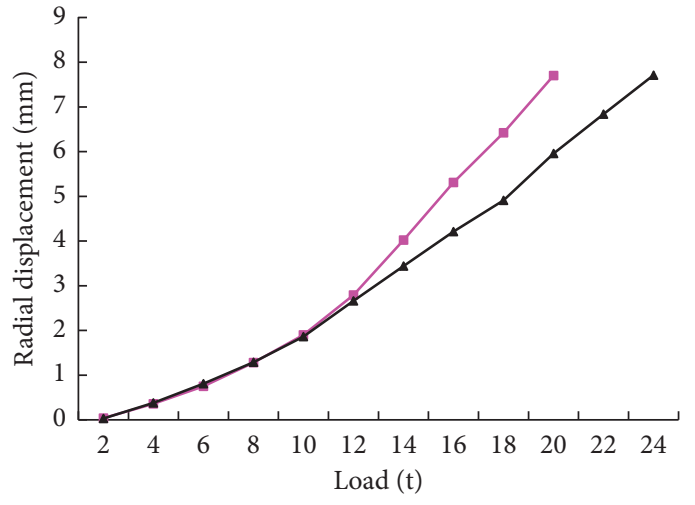

$\rightarrow$ Reinforced concrete

$\rightarrow$ Basalt fiber-reinforced concrete

(b)

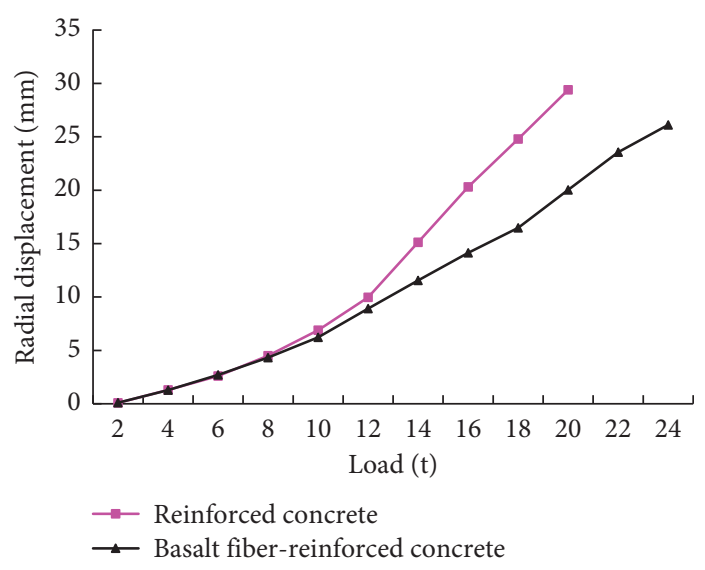

(d)

FIGURE 13: Change curve of the radial displacement and load. (a) Measuring point 1-vault, (b) measuring point 2-haunch, (c) measuring point 3-middle of side wall, and (d) measuring point 4-middle of inverted arch.

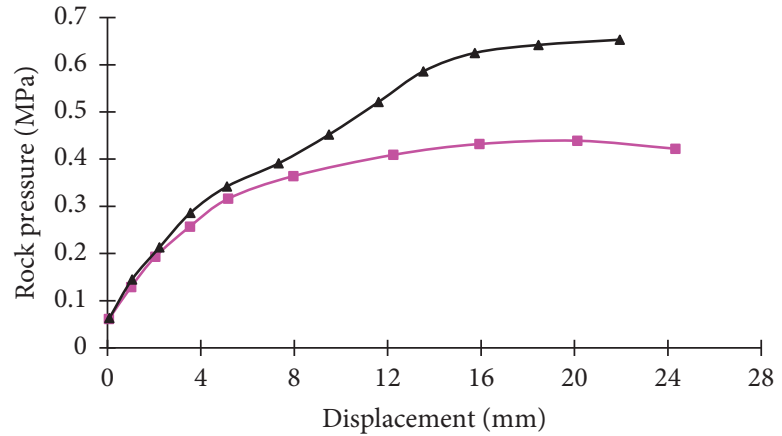

Reinforced concrete

Basalt fiber-reinforced concrete

(a)

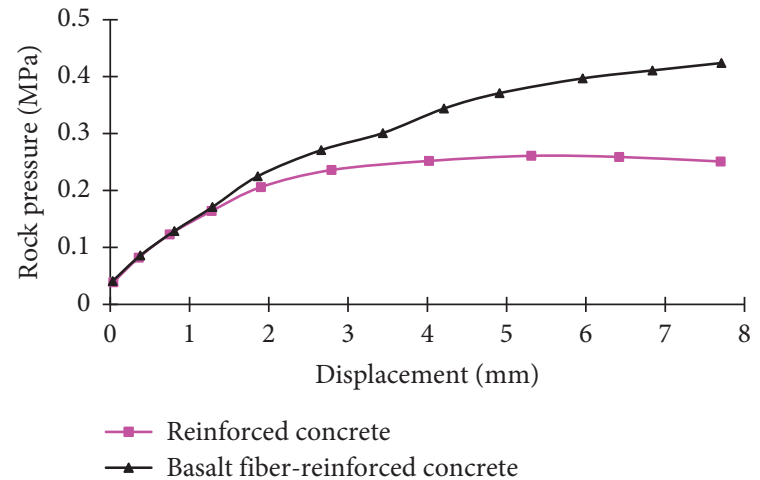

(b)

Figure 14: Continued. 


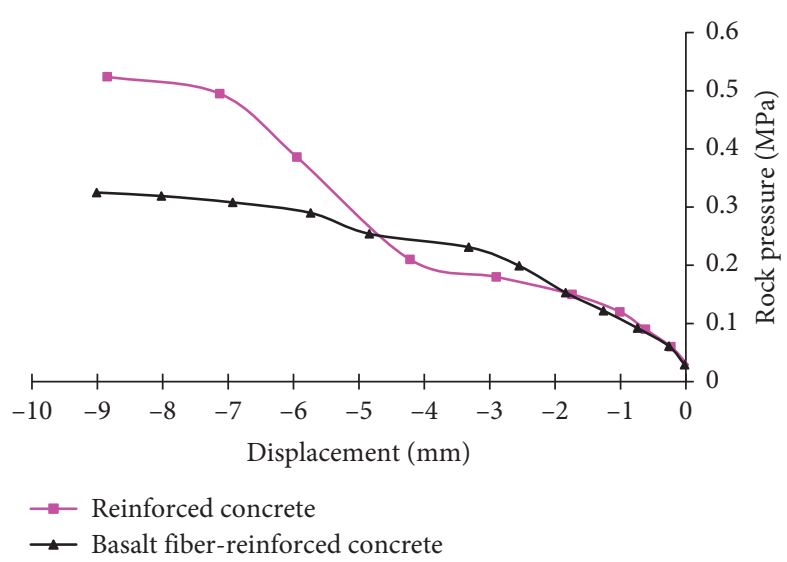

(c)

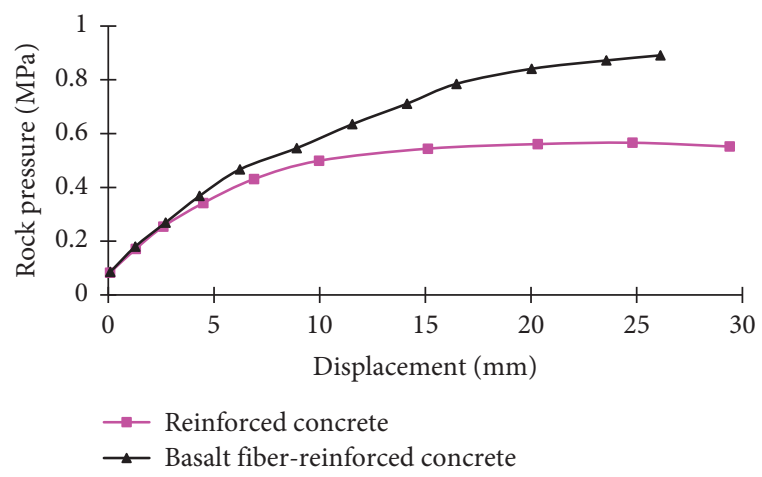

(d)

FIGURE 14: Bearing characteristic curve of lining structure. (a) Measuring point 1-vault, (b) measuring point 2-haunch, (c) measuring point 3 -middle of side wall, and (d) measuring point 4-middle of inverted arch.

structure is still high. When loaded with 2 times the initial cracking load, the lining structure still has a certain bearing capacity. Compared with reinforced concrete lining, the bearing capacity and deformation control capacity of basalt fiber-reinforced concrete lining are significantly improved.

\subsubsection{External Deformation Measuring Point-Middle of Side} Wall. During the loading process, the lining of the side wall deforms towards the surrounding rock, which will be affected by the reaction of the surrounding rock, resulting in the increasing radial pressure of the relevant parts of the lining.

Because of the toughness and crack resistance of basalt fiber-reinforced concrete, the radial displacement in the middle of side wall is less than $10 \%$ 20\% of the reinforced concrete under the same load condition when reaching the initial crack load, and the basalt fiber-reinforced concrete lining can still bear a large bending moment when reaching the initial crack load. Because the radial displacement in the middle of the lining side wall with basalt fiber-reinforced concrete is small, the radial pressure is also small (compared with reinforced concrete).

\section{Conclusion}

(1) When the main load direction is vertical, the first longitudinal crack appears in the middle of the inverted arch or the inner side of the vault. The initial crack load of reinforced concrete lining is $10 \mathrm{t}$, and basalt fiber-reinforced concrete lining is $12 \mathrm{t}$. Due to the inhibition of basalt fiber, the path of crack development is tortuous, which ultimately delays the damage of lining. When the reinforced concrete lining is loaded to 2 times of the initial crack load, the structure is damaged and finally 9 cracks are generated; when the basalt fiber-reinforced concrete lining is loaded to 2 times of the initial crack load, there are still no through cracks in the lining structure and the number of cracks has reached 13.
(2) The actual radial pressure acting on the lining structure is about $30 \% \sim 40 \%$ less than the theoretical calculation value, which is mainly shared by the surrounding rock. Owing to the good crack resistance and deformation control ability of basalt fiber, the stress of lining is more uniform than that of reinforced concrete after the initial crack load is reached.

(3) Before the initial crack load is reached, the radial displacement is basically linear with the increase of load; after reaching the initial crack load, the growth rate of radial displacement increases obviously and the reinforced concrete lining is larger than the basalt fiber-reinforced concrete lining. When basalt fiber is added into the lining structure, the toughness of the lining structure is enhanced and the lining can still bear large bending moment and reduce the deformation rate of the structure after reaching the initial crack load.

(4) Before the initial crack of lining is appeared, the bearing characteristic curve of reinforced concrete and basalt fiber-reinforced concrete lining basically changes in line. After the initial crack is appeared, the bearing characteristic curve of the reinforced concrete lining rises slowly and tends to convergence rapidly; the bearing characteristic curve of the basalt fiber-reinforced concrete lining rises slowly, and there is no sign of convergence when it reaches 2 times of the initial crack load.

\section{Data Availability}

The data used to support the findings of this study are included within the article.

\section{Conflicts of Interest}

The authors declare that there are no conflicts of interest regarding the publication of this paper. 


\section{Acknowledgments}

The authors appreciate the support from the National Natural Science Foundation of China (Nos. 51408008 and 51478277).

\section{References}

[1] G. Barla, M. Bonini, and M. Semeraro, "Analysis of the behaviour of a yield-control support system in squeezing rock," Tunnelling and Underground Space Technology, vol. 26, no. 1, pp. 146-154, 2011.

[2] W. Yu, W. Wang, X. Chen, and S. Du, "Field investigations of high stress soft surrounding rocks and deformation control," Journal of Rock Mechanics and Geotechnical Engineering, vol. 7, no. 4, pp. 421-433, 2015.

[3] G. Anagnostou, "A model for swelling rock in tunnelling," Rock Mechanics and Rock Engineering, vol. 26, no. 4, pp. 307-331, 1993.

[4] C. L. Xin, Z. Z. Wang, J. M. Zhou, and B. Gao, "Shaking table tests on seismic behavior of polypropylene fiber reinforced concrete tunnel lining," Tunnelling and Underground Space Technology, vol. 88, pp. 1-15, 2019.

[5] G. Tiberti, F. Minelli, and G. Plizzari, "Reinforcement optimization of fiber reinforced concrete linings for conventional tunnels," Composites Part B: Engineering, vol. 58, pp. 199-207, 2014.

[6] Z. Z. Wang, L. Jiang, and Y. Gao, "Shaking table test of seismic response of immersed tunnels under effect of water," Soil Dynamics and Earthquake Engineering, vol. 116, pp. 436-445, 2019.

[7] H. J. Zhang, Z. Z. Wang, F. Lu, G. Y. Xu, and W. G. Qiu, "Analysis of the displacement increment induced by removing temporary linings and corresponding countermeasures," Tunnelling and Underground Space Technology, vol. 73, pp. 236-243, 2018.

[8] N. Buratti, C. Mazzotti, and M. Savoia, "Post-cracking behaviour of steel and macro-synthetic fibre-reinforced concretes," Construction and Building Materials, vol. 25, no. 5, pp. 2713-2722, 2011.

[9] Z. Wang, X.-L. Zhao, G. Xian, G. Wu, R. K. Singh Raman, and S. Al-Saadi, "Durability study on interlaminar shear behaviour of basalt-, glass- and carbon-fibre reinforced polymer (B/ G/CFRP) bars in seawater sea sand concrete environment," Construction and Building Materials, vol. 156, pp. 985-1004, 2017.

[10] T. M. Borhan, "Properties of glass concrete reinforced with short basalt fibre," Materials and Design, vol. 42, pp. 265-271, 2012.

[11] T. Kasper, C. Edvardsen, G. Wittneben, and D. Neumann, "Lining design for the district heating tunnel in Copenhagen with steel fibre reinforced concrete segments," Tunnelling and Underground Space Technology, vol. 23, no. 5, pp. 574-587, 2008.

[12] H.-H. Lee, "Shear strength and behavior of steel fiber reinforced concrete columns under seismic loading," Engineering Structures, vol. 29, no. 7, pp. 1253-1262, 2007.

[13] W.-m. Song, Research of Impermeability and Anti-Cracking Properties of Tunnel Secondary Lining Fiber Concrete, Central South University, Chansha, China, 2013.

[14] J. Branston, S. Das, S. Y. Kenno, C. Taylor, and C. Taylor, "Mechanical behaviour of basalt fibre reinforced concrete," Construction and Building Materials, vol. 124, pp. 878-886, 2016.
[15] Y. V. Lipatov, S. I. Gutnikov, M. S. Manylov, E. S. Zhukovskaya, and B. I. Lazoryak, "High alkali-resistant basalt fiber for reinforcing concrete," Materials \& Design, vol. 73, pp. 60-66, 2015.

[16] C. High, H. M. Seliem, A. El-Safty, and S. H. Rizkalla, "Use of basalt fibers for concrete structures," Construction and Building Materials, vol. 96, pp. 37-46, 2015.

[17] G. Campione, L. La Mendola, A. Monaco, A. Valenza, and V. Fiore, "Behavior in compression of concrete cylinders externally wrapped with basalt fibers," Composites Part B: Engineering, vol. 69, pp. 576-586, 2015.

[18] V. Brik, V. Ramakrishnan, and N. Tolmare, Performance Evaluation of 3-D Basalt Fibre Reinforced Concrete \& Basalt Rod Reinforced Concrete, IDEA Program Final Report, Contract No. NCHRP-45, Transportation Research Board, Washington, DC, USA, 1998.

[19] H. Wang, L. Yuan, and H. Song, "Experimental study on mechanical property of chopped basalt fiber reinforced concrete," Building Structure, vol. 43, no. S2, pp. 562-564, 2013.

[20] J. Lian, Y. Yang, M. Yang, and Y. Zhao, "Experimental research on the mechanical behavior of chopped basalt fiber reinforced concrete," Industrial Construction, vol. 137, no. 6, pp. 8-10, 2007.

[21] J. Sim, C. Park, and D. Y. Moon, "Characteristics of basalt fiber as a strengthening material for concrete structures," Composites Part B: Engineering, vol. 36, no. 6-7, pp. 504-512, 2005.

[22] M. Peng, H. Huang, Q.-h. Liao, and J.-c. Wang, “Test study on basic mechanical properties of basalt fiber reinforced concrete," Concrete, vol. 33, no. 1, pp. 74-75, 2012.

[23] T. Ayub, N. Shafiq, and M. F. Nuruddin, "Mechanical properties of high-performance concrete reinforced with basalt fibers," Procedia Engineering, vol. 77, pp. 131-139, 2014.

[24] C. Jiang, K. Fan, F. Wu, and D. Chen, "Experimental study on the mechanical properties and microstructure of chopped basalt fibre reinforced concrete," Materials \& Design, vol. 58, pp. 187-193, 2014. 